Article

\title{
Do Silvi-Medicinal Plantations Affect Tree Litter Decomposition and Nutrient Mineralization?
}

\author{
Xiaoxi Zhang ${ }^{1,2, *(\mathbb{D}, \text { Hangyu Lei }}{ }^{1}$, Yujie Chong ${ }^{1}$, Jiawei Hu ${ }^{1}$, Wenrong Che ${ }^{1}$, Man Hu ${ }^{1}$, \\ Shuoyu $\mathrm{Xu}^{1}{ }^{1}$, Pan Zhang ${ }^{1}$, Lingling Zhang ${ }^{1}$, Jiyuan $\mathrm{Xu}^{2}$ and Zengwen Liu ${ }^{3}$,* \\ 1 Shaanxi Key Laboratory of Chinese Jujube (Yan'an University), College of Life Sciences, Yan'an University, \\ Yan'an 716000, China; hylei19@163.com (H.L.); bqyj08@163.com (Y.C.); jwhu19@163.com (J.H.); \\ wrche19@163.com (W.C.); mhu19@163.com (M.H.); syxu19@163.com (S.X.); pzhang19@163.com (P.Z.); \\ llzhang19@163.com (L.Z.) \\ 2 Institute of Soil and Water Conservation, Northwest A\&F University, Yangling 712100, China; \\ yzxu_jiyuan2014@163.com \\ 3 College of Natural Resources and Environment, Northwest A\&F University, Yangling 712100, China \\ * Correspondence: zhangxiaoxi712100@gmail.com (X.Z.); zengwenliu2003@aliyun.com (Z.L.)
}

Received: 4 July 2019; Accepted: 16 September 2019; Published: 19 September 2019

\begin{abstract}
In a silvi-medicinal system, the plant secondary metabolites (PSMs) released from medicinal herbs could affect tree litter decomposition and nutrient release. However, the specific effects of PSMs on arboreous litter decomposition are still not well understood. In this study, the extracts of nine types of medicinal herbs were used to treat Pinus armandii Franch. and Larix gmelinii (Rupr.) Kuzen. litter during a simulated half-year decomposition. The effects of the extracts on the decomposition and the $\mathrm{N}$ and $\mathrm{P}$ release of the conifer litter were investigated. The results indicated that most of the medicinal herb extracts significantly inhibited the late decomposition of $P$. armandii litter, whereas only two of them accelerated the entire decomposition process. Only a few significantly affected the decomposition of the L. gmelinii litter. Four of the nine types of extract significantly inhibited the $\mathrm{N}$ and $\mathrm{P}$ release of the P. armandii litter, while $3 / 9$ and 6/9 inhibited the $\mathrm{N}$ and $\mathrm{P}$ release of the L. gmelinii litter, respectively. The accelerating effects of the extracts on the cellulase activity and the inhibitory effects on the polyphenol oxidase activity might be responsible for the early acceleration and late inhibition of litter decomposition, while the effects of the extracts on the activities of protease and phosphatase might not be the main reason for the inhibitory or accelerating effects on the $\mathrm{N}$ and $\mathrm{P}$ release. In general, the inhibitory effects of medicinal herbs on the nutrient cycling of ecosystems should be taken into consideration when building silvi-medicinal systems, especially in P. armandii forests.
\end{abstract}

Keywords: silvi-medicinal system; litter decomposition; conifer forests; plant secondary metabolites

\section{Introduction}

Herbal medicine is one of the foundations of traditional medicine in various regions worldwide and plays crucial roles in disease treatment and primary health care [1,2]. In recent decades, with an increasing understanding of their pharmacological mechanisms, the exploitation and utilization of herbal medicines have exhibited trends of increasing standardization and scientificalization. The injection or oral administration of the purified effective components is replacing traditional crude drug processing and oral decoction [3]. Due to the identification of therapeutic effects, the plantation of herbal medicines has developed rapidly and extended to Europe and America from traditional producing areas such as East, Southeast or Central Asia [2,4-6]. However, medicinal herb plantations require a relatively specific temperature, air humidity, illumination and soil conditions. In addition, 
these herbs usually need to be planted for several years to attain a favorable quality [7]. Consequently, the plantation of medicinal herbs usually occupies agricultural land over the long term. Additionally, sufficient agricultural facilities are needed to obtain suitable environmental factors. More importantly, the long-term plantation of some medicinal herbs causes serious soil degradation, hindering the subsequent use of farmland [7-9]. The abovementioned issues have led to agricultural land shortages and high economic inputs. Hence, developing new plantation patterns is one of the most urgent demands in the sustainable development of medicinal herb plantations.

The Qinling Mountains are one of the most important producing areas of Chinese traditional medicinal materials. This region has favorable climatic conditions for the growth of medicinal herbs, and consequently, abundant plant resources are found here [10]. However, due to the historical excessive cutting and subsequent artificial afforestation, the existing natural and artificial forests usually exhibit obvious deficiencies, such as a poor biodiversity, unbalanced soil nutrients and soil degradation. It is urgent to introduce undergrowth plants to improve the stability and productivity of these pure forests [11]. Considering that many medicinal herbs are shade-tolerant and that pure forests can provide a favorable climatic environment, developing understory herb plantations might be a feasible way to relieve land shortages, reduce economic inputs, and increase the productivity and biodiversity of pure forests [7,12].

In developing understory plantations, the effects of medicinal herbs on the growth of trees should be considered in addition to the competition for nutrients, water and light between trees and understory species [12]. Because medicinal plants might affect decomposition and nutrient release from litter, they could also affect tree growth, which relies on nutrients from decomposition [13]. Litter decomposition is performed through the cooperation of soil fauna, microbes and the enzymes they secrete. However, plant-derived secondary metabolites might significantly inhibit microbial growth and related enzymatic activities. For instance, terpenoid substances significantly inhibit fungal growth and the activities of protease, glucosidase, and phosphatase, which participate in the decomposition of plant litter. They were also found to be antifeedants to soil fauna [14,15]. Phenolic substances and their derivatives can selectively hinder the growth of certain microbial species and decrease their diversity and carbon metabolism ability [16-18]. Some flavone substances also exhibit inhibitory effects on the growth of fungi [19]. Hence, in view of the abundant secondary metabolites in medicinal herbs, the components leached by precipitation might hinder the decomposition of litter by inhibiting the activities of microbes and enzymes and, consequently, the long-term stability of forest ecosystems. In the existing literature, many researchers have reported the inhibitory effects of plant secondary metabolites (PSMs) on litter decomposition; however, most of them addressed only the effects of endogenous PSMs [20,21] or the effects of one or several types of artificially added PSMs [14,16,22-24]. The effects of PSMs from living plants, especially those that are leached by natural precipitation, with a low concentration and complex components, remain less well understood.

In this study, litter from Pinus armandii Franch. and Larix gmelinii (Rupr.) Kuzen., two typical conifer species of the artificial forests in the Qinling Mountains region, were intermittently treated with the water extracts of nine types of medicinal herbs in order to determine how the PSMs leached from medicinal herbs affect the litter decomposition of the two conifer species. We hypothesized that the medicinal herb extract treatments would significantly inhibit the decomposition of the conifer litters.

\section{Materials and Methods}

\subsection{Litter and Soil Sampling}

The samples were collected from the Houzhenzi forest farm, located in Zhouzhi County, China $\left(108^{\circ} 44^{\prime}-108^{\circ} 57^{\prime} \mathrm{E}, 33^{\circ} 46^{\prime}-33^{\circ} 57^{\prime} \mathrm{N}\right.$, altitude $\left.1300-2650 \mathrm{~m}\right)$, with a warm-temperature, humid continental monsoon climate. The mean annual temperature is $6.4{ }^{\circ} \mathrm{C}$, and the mean annual precipitation is $1001.7 \mathrm{~mm}$, which is concentrated from July to September. The soil is classified as mountain brown earth, with an available nitrogen concentration of $110.37 \mathrm{mg} \cdot \mathrm{kg}^{-1}$, an available 
phosphorus concentration of $2.23 \mathrm{mg} \cdot \mathrm{kg}^{-1}$, an available phosphorus concentration of $146.59 \mathrm{mg} \cdot \mathrm{kg}^{-1}$ and an organic matter concentration of $21.93 \mathrm{~g} \cdot \mathrm{kg}^{-1}$. The $\mathrm{pH}$ is 6.27 , the soil moisture content is $13.39 \%$, and the saturated field water holding capacity is $28.57 \%$. In late autumn, two types of fresh foliar litter were collected from typical mature forests of P. armandii and L. gmelinii using litter traps. The litters were cleaned with brushes and subsequently air-dried and cut into $1.5 \mathrm{~cm}$ debris to accelerate the subsequent decomposition experiments. To determine the initial $C$ concentration, crushed litter was digested using concentrated sulfuric acid and potassium dichromate solutions. Subsequently, the solution was titrated with a ferrous sulfate solution, and the litter $C$ concentration was calculated based on the ferrous sulfate solution consumption, according to the method of Zhang et al. [25]. For the determination of $\mathrm{N}$ and $\mathrm{P}$, crushed litter was digested using concentrated sulfuric acid and hydrogen peroxide, and then the solution was diluted and determined using a continuous flow analytical system (AA3, Bran Luebbe, Germany) to obtain its $\mathrm{N}$ concentration [25]. Simultaneously, a $\mathrm{NaOH}$ solution was gradually added to the untreated diluted solution containing a dinitrophenol indicator until its color turned yellow. Subsequently, the color-changed solution was mixed with a vanadium ammonium molybdate solution and determined using an ultraviolet-visible spectrophotometer (UV-2450, Shimadzu Corporation, Kyoto, Japan) at $440 \mathrm{~nm}$ [25]. For the determination of lignin, crushed litter was first soaked with acetic acid and acetone, and centrifuged, and then the sediments were digested with sulfuric acid and potassium dichromate solutions, and titrated with a ferrous sulfate solution. Finally, the litter lignin concentration was calculated based on the ferrous sulfate solution consumption according to the method of Zhang et al. [25]. Based on these methods, the initial substrate quality of each type of litter was calculated and is listed in Table 1.

Table 1. The initial substrate quality of the needle litters.

\begin{tabular}{|c|c|c|c|c|c|c|c|}
\hline \multirow{2}{*}{$\begin{array}{l}\text { Needle } \\
\text { Litters }\end{array}$} & \multicolumn{4}{|c|}{ Concentration $\left(\mathrm{mg} \cdot \mathrm{g}^{-1}\right)$} & \multirow{2}{*}{$\mathrm{C} / \mathrm{N}$} & \multirow{2}{*}{$\mathrm{C} / \mathrm{P}$} & \multirow{2}{*}{ Lignin/N } \\
\hline & $\mathrm{C}$ & $\mathbf{N}$ & $\mathbf{P}$ & Lignin & & & \\
\hline P. armandii & $446.46 \pm 10.56$ & $11.05 \pm 0.83 *$ & $0.83 \pm 0.01 *$ & $264.66 \pm 5.38 *$ & $40.40 *$ & $538.5^{*}$ & $23.95 *$ \\
\hline L. gmelinii & $455.63 \pm 8.95$ & $20.86 \pm 0.45$ & $0.72 \pm 0.01$ & $198.51 \pm 3.67$ & 21.84 & 631.07 & 9.52 \\
\hline
\end{tabular}

In the peak growing season in the following year (July to August), the medicinal herbs (aboveground parts) were sampled, including Taraxacum mongolicum Hand.-Mazz. (TM), Corydalis bungeana Turcz. (CB), Mentha haplocalyx Briq., Houttuynia cordata Thunb. (HC), Asarum sieboldii Miq. (AS), Lonicera japonica Thunb. (LJ), Nepeta cataria L. (NC), Gynostemma pentaphyllum (Thunb.) Makino (GP), and Prunella vulgaris L. (PV). The samples were air-dried and crushed to pass through a $1 \mathrm{~mm}$ sieve. In addition, the soil from the $0-10 \mathrm{~cm}$ layer of the tree-free land near the forests was collected as decomposition medium to avoid the "home field effect" (that is, plant litter tends to decompose more rapidly in the habitat from which it was derived than in other habitats) of forest soil. The collected soil was passed through a $5 \mathrm{~mm}$ sieve and appropriately air-dried for a humidity control in the subsequent decomposition experiments.

Two days before the beginning of the decomposition experiment, a powder of the medicinal herbs was extracted using $20^{\circ} \mathrm{C}$ distilled water (approximately equal to the temperature of natural rainwater in summer, data from personal communication) with a ratio of $80 \mathrm{~g}$ of powder to $1 \mathrm{~L}$ of water for $12 \mathrm{~h}$. The concentration of the powdered leaves in the extraction water was $80 \mathrm{mg} \mathrm{mL}^{-1}$, which was selected according to the precipitation for July and August, as well as the biomass of the herbs detected during this period. The extracts were filtered twice with 4 layers of gauze, centrifuged at $1500 \times g$ for $10 \mathrm{~min}$, and then stored at $4{ }^{\circ} \mathrm{C}$. Before treating the litters, the refrigerated extracts were uniformly warmed to $20^{\circ} \mathrm{C}$ and shaken for $30 \mathrm{~min}$ to avoid a possible chemical precipitation caused by a low temperature.

Certainly, the concentration of chemicals in the extracts from the powdered leaves in the present study would be higher than those in the natural leachates of intact living plants. However, because 
the plant residues were not processed at a high temperature and because of the short-term extraction and the attenuation and adsorption of chemicals by the soil during infiltration, the actual composition and amount of chemicals that came into contact with the litter during the extract treatment was approximately equal to that in natural leachates.

\subsection{Litter Decomposition}

The prepared needle litters were placed into $10 \mathrm{~cm} \times 20 \mathrm{~cm}$ litterbags with $0.25 \times 0.25 \mathrm{~mm}$ mesh. The dimensions of the mesh were smaller than those of the needles; thus, only a small amount of litter leaked from the bags. A total of 150 litterbags containing $6 \mathrm{~g}$ of P. armandii litter were prepared. Groups of five litterbags were then separately buried in $20 \mathrm{~cm} \times 40 \mathrm{~cm} \times 20 \mathrm{~cm}$ plastic pots containing $3 \mathrm{~kg}$ of soil. A total of 30 pots containing the same type of litter were prepared. Subsequently, each set of three pots was treated with one type of extract $(150 \mathrm{~mL})$ by spraying. The soil moisture was adjusted to approximately $50 \%$ of the saturated field water holding capacity, which was slightly higher than the natural soil moisture. The three pots sharing the same type of extract were used to simulate three independent decomposition processes, that is, three replications. The remaining three pots were treated with distilled water and used for control testing. The uncovered pots were then incubated at $20-25^{\circ} \mathrm{C}$ for 6 months. During the incubation, $150 \mathrm{~mL}$ of extract or distilled water was sprayed into the corresponding pots twice a month. According to the preliminary experiment, the total evaporation in one pot every two weeks was approximately $150 \mathrm{~mL}$. The L. gmelinii litter was also processed as described above.

\subsection{Litter Chemical Analyses and Enzyme Activities}

During the incubation, the litterbags were retrieved 5 times in the 1st, 2nd, 3rd, 5th and 6th months. Only one bag was randomly retrieved from the 5 bags in the same pot in one sampling, and the three bags from the pots sharing the same treatments were treated as replicates. The litters were transferred into a $0.15 \mathrm{~mm}$ sieve, rinsed quickly and then oven-dried at $60^{\circ} \mathrm{C}$ to a constant weight. Subsequently, the $\mathrm{N}$ and $\mathrm{P}$ contents of the litters were determined according to the abovementioned methods of Zhang et al. [25] using an AA3 continuous flow analyzer and an ultraviolet spectrophotometer, respectively. In addition, the soil in each pot was sampled three times after 1,3, and 6 months of decomposition to determine the enzymatic activities, and the three soil samples sharing the same treatments were used as replicates.

The activities of sucrase and carboxymethyl cellulase (CMCase) were detected using 3,5-dinitrosalicylic acid colorimetry. Briefly, the soil sample was incubated with sucrose or carboxymethyl cellulose solution, phosphate buffer and methylbenzene at $37^{\circ} \mathrm{C}$ for $24 \mathrm{~h}$. The released glucose was reacted with dinitrosalicylic acid and then spectrophotometrically quantified at $508 \mathrm{~nm}$ using a UV-VIS spectrophotometer (UV-2450, Shimadzu Corporation, Japan). The $\beta$-glucosidase activity was detected using nitrophenol colorimetry. The soil sample was incubated with a nitrobenzene- $\beta$ D-glucoside solution, citric acid-phosphate buffer, methylbenzene and distilled water at $30^{\circ} \mathrm{C}$ for $1 \mathrm{~h}$. Subsequently, ethanol was added, and the mixture was filtered. The released nitrophenol was reacted with a 2-amino-2-(hydroxymethyl)-3-propanediol solution and spectrophotometrically quantified at $400 \mathrm{~nm}$. The polyphenol oxidase activity was detected using pyrogallol colorimetry. The soil sample was incubated with a pyrogallol solution at $30^{\circ} \mathrm{C}$ for $2 \mathrm{~h}$, mixed with citric acid-phosphate buffer and diethyl ether, and shaken for $30 \mathrm{~min}$. Finally, the supernatant was spectrophotometrically determined at $430 \mathrm{~nm}$. The protease activity was detected using ninhydrin colorimetry. The soil sample was incubated with a casein solution and methylbenzene at $30^{\circ} \mathrm{C}$ for $2 \mathrm{~h}$, mixed with sulfuric acid and sodium sulfate solutions, and then centrifuged. The released aminoacetic acid was reacted with ninhydrin and spectrophotometrically determined at $508 \mathrm{~nm}$. The phosphatase activity was detected using disodium phenyl phosphate colorimetry. The soil sample was incubated with a disodium phenyl phosphate solution and methylbenzene at $37^{\circ} \mathrm{C}$ for $2 \mathrm{~h}$. The released phenol was reacted with 4 -aminophenazon and potassium ferricyanide in an ammonium chloride-ammonium hydroxide buffer 
and then spectrophotometrically determined at $510 \mathrm{~nm}$. The activities were represented as the product production per day catalyzed by one gram of soil, that is, the production of glucose $(\mathrm{mg})$, nitrophenol (mmol), purpurogallin (mg), $\mathrm{NH}_{2}-\mathrm{N}(\mathrm{mg})$ and $\mathrm{P}_{2} \mathrm{O}_{5}(\mathrm{mg})$ [25].

The qualitative analyses of the PSMs in the medicinal herb extracts were conducted with a gas chromatograph-mass spectrometer, and the detected PSMs are listed in Table 2. In addition, the total $\mathrm{N}$ and $\mathrm{P}$ concentrations were determined using the abovementioned methods [25] and are listed in Table 2 as well.

Table 2. The main plant secondary metabolites detected and the nutrient concentrations in the medicinal herb extracts.

\begin{tabular}{|c|c|c|c|}
\hline $\begin{array}{l}\text { Extracts of Medicinal } \\
\text { Herbs }\end{array}$ & Detected Metabolites * & $\begin{array}{l}\text { N Concentration } \\
\left(\mathrm{mg} \mathrm{L}^{-1}\right)\end{array}$ & $\begin{array}{l}\text { P Concentration } \\
\left(\mathrm{mg} \mathrm{L}^{-1}\right)\end{array}$ \\
\hline T. mongolicum & $\begin{array}{l}\text { 24,25-Dihydroxycholecalciferol; Caffeic acid; Camphor; } \\
\text { Caryophyllene; Chlorogenic acid; Mignonette; Quercetin; }\end{array}$ & $24.53 \pm 1.13$ & $2.72 \pm 0.12$ \\
\hline C. bungeana & $\begin{array}{l}\text { 2,3-Dihydrobenzofuran; 3-Oxygen- } \beta \text {-ionone; } \\
\text { 4-(3-Hydroxybutyl)-3,5,5-trimethyl-2-cyclohexene-1-ketone; } \\
\text { 4-Hydroxy-3,5,6-trimethyl-4-(3-oxo-1-butenyl)-2-cyclohexene-1-ketone; } \\
\text { Coniferyl alcohol; Linalool; } \beta \text {-Pinene; } \beta \text {-Sitosterol }\end{array}$ & $23.58 \pm 1.49$ & $1.14 \pm 0.97$ \\
\hline H. cordata & $\begin{array}{l}\text { (2S,3S)-2-Amino-3-methylpentanoic acid; Aporphines; Artemisinin; } \\
\text { Caryophyllene; Chlorogenic acid; Cineole; DL-Limonene; } \\
\text { Hyperoside; Isorhamnetin; Kaempferol-3-O- } \beta \text {-D-glucoside; } \\
\text { L-glutamic acid; Linalool; Linoleic acid; Methyl-nonylketone; } \\
\text { Myrcene; Ocimene; Palmitic acid; Pyridine; Quercetin; Rutin; } \\
\text { Stearic acid; } \alpha \text {-Pinene; } \beta \text {-Sitosterol }\end{array}$ & $22.19 \pm 1.35$ & $2.28 \pm 0.74$ \\
\hline L. japonica & $\begin{array}{l}\text { 1,6-Anhydro- } \beta \text {-D-glucopyranose; } 2 \text {-Vinylpyridine; } \\
\text { 3-tert-Butyl-4-hydroxyanisole; Allose; Benzyl alcohol; Benzyl } \\
\text { benzoate; Borneol; Limonene; Linalool; Palmitic acid; Phenethyl } \\
\text { alcohol; Phenylacetaldehyde; }\end{array}$ & $25.40 \pm 0.93$ & $2.64 \pm 0.34$ \\
\hline N. cataria & $\begin{array}{l}\text { (+)-Dipentene; } 1 \text {-Octen-3-ol; 1-Octen-3-yl acetate; Caryophyllene } \\
\text { oxide; Isomenthone; Menthenone; Menthone; Menthone; Palmitic } \\
\text { acid; Pyridazine; } \beta \text {-Sitosterol }\end{array}$ & $10.12 \pm 0.67$ & $0.54 \pm 0.02$ \\
\hline G. pentaphyllum & $\begin{array}{l}\text { Arachidic Acid; Benzaldehyde; Diisobutyl phthalate; } \\
\text { Dodecenylsuccinic acid; Fitone; Geranylacetone; Linalool; } \\
\text { Naphthalene; Palmitic acid; Pentadecanoic acid; } \beta \text {-Sitosterol }\end{array}$ & $12.56 \pm 1.69$ & $0.71 \pm 0.04$ \\
\hline
\end{tabular}

* All detected plant secondary metabolites are listed in alphabetical order because no quantitative data about their specific contents were detected in this study. This list was used to analyze the possible inhibitory effects of herb extracts on litter-decomposing microbes and enzymes based on the related literature (Table S1).

\subsection{Data Processing}

The decomposition process was fitted according to a modified Olson model (Equation 1) using the Sigma Plot 12.5 software, and the time required for a $95 \%$ or $50 \%$ litter decomposition $\left(T_{0.95}\right.$ and $T_{0.50}$ ) was calculated using the software-built calculation module:

$$
R=a e^{-k_{1} t}+b e^{-k_{2} t},(a+b=1)
$$

where $R$ is the mass remaining rate of the litter, $a$ and $b$ indicate the calculated relative mass proportions of recalcitrant and liable components in the litter, $k_{1}$ and $k_{2}$ indicate their respective decomposition constants, and $t$ is the decomposition duration (year).

In addition, a repeated-measures ANOVA was conducted to determine the effects of the decomposition duration (DD, repeated factor), treatment (extracts), and their interactions on the remaining mass of $\mathrm{N}$ and $\mathrm{P}$ in the conifer litters and the activity of the related soil enzymes. 
When the result of the Mauchly's test of sphericity was $p<0.01$, the results were adjusted using Greenhouse-Geisser's correction coefficient. A one-way ANOVA was conducted to analyze the significance of the differences among treatments when the interaction effects between the treatment and decomposition duration or the temporal effects were significant, and the least significant differences method was employed for the subsequent post hoc analyses $(p<0.05)$. Sigma Plot 12.5 was employed for drafting.

\section{Results}

\subsection{Effects on the Decomposition of Conifer Litters}

The curve fitting results indicated that the modified Olson model exhibited a favorable accuracy in fitting the decomposition process, with determination coefficients larger than 0.87 . In addition, all the fitting results passed the significance tests. According to these results (Table 3), only TM extracts did not affect the decomposition of the P. armandii litter. The extracts of $\mathrm{CB}, \mathrm{MH}, \mathrm{LJ}$ and PV significantly $(p<0.05)$ accelerated the first half of the decomposition, while they significantly $(p<0.05)$ inhibited the second half of the decomposition of the P. armandii litter. The NC and GP extracts significantly $(p<0.05)$ inhibited only the second half of the decomposition, while the HC and AS extracts significantly $(p<0.05)$ accelerated the entire decomposition process of the P. armandii litter. Comparatively, the decomposition of the L. gmelinii litter was affected by very few medicinal herb extracts (Table 4); only the HC extract significantly $(p<0.05)$ accelerated the first half of its decomposition, but the same extract exhibited a significant inhibition in the second half. The NC extracts significantly $(p<0.05)$ inhibited only the second-half decomposition of the L. gmelinii litter, while the GP extracts exhibited the opposite effects.

Table 3. The $95 \%$ decomposition period $\left(T_{0.95}\right)$ and half-life period $\left(T_{0.50}\right)$ of $P$. armandii litter decomposition under different treatments.

\begin{tabular}{cccc}
\hline Medicinal Herb Extract & Litter Decomposition Model & $\boldsymbol{T}_{\mathbf{0 . 9 5}} \mathbf{( y \mathbf { r } )}$ & $\boldsymbol{T}_{\mathbf{0 . 5 0}}(\mathbf{y r})$ \\
\hline T. mongolicum & $R=0.29 \mathrm{e}^{-8.86 t}+0.71 \mathrm{e}^{-0.22 t}$ & $19.90 \pm 2.58$ & $2.67 \pm 0.60$ \\
C. bungeana & $R=0.29 \mathrm{e}^{-9.36 t}+0.71 \mathrm{e}^{-0.22 t}$ & $13.16 \pm 2.27$ & $1.71 \pm 0.42^{*}$ \\
M. haplocalyx & $R=0.17 \mathrm{e}^{-11.26 t}+0.83 \mathrm{e}^{-0.46 t}$ & $13.34 \pm 2.19$ & $1.74 \pm 0.41^{*}$ \\
H. cordata & $R=0.22 \mathrm{e}^{-17.88 t}+0.78 \mathrm{e}^{-0.49 t}$ & $7.78 \pm 1.79 *$ & $1.24 \pm 0.22^{* *}$ \\
A. sieboldii & $R=0.22 \mathrm{e}^{-9.84 t}+0.78 \mathrm{e}^{-0.28 t}$ & $9.16 \pm 1.82^{*}$ & $1.44 \pm 0.37^{* *}$ \\
L. japonica & $R=0.30 \mathrm{e}^{-10.16 t}+0.71 \mathrm{e}^{-0.11 t}$ & $10.79 \pm 1.82$ & $1.73 \pm 0.38^{*}$ \\
N. cataria & $R=0.28 \mathrm{e}^{-13.07 t}+0.72 \mathrm{e}^{-0.13 t}$ & $23.80 \pm 0.76^{* *}$ & $3.07 \pm 0.12$ \\
G. pentaphyllum & $R=0.24 \mathrm{e}^{-10.78 t}+0.75 \mathrm{e}^{-0.33 t}$ & $21.18 \pm 1.42 *$ & $2.90 \pm 0.32$ \\
P. vulgaris & $R=0.19 \mathrm{e}^{-49.73 t}+0.81 \mathrm{e}^{-0.25 t}$ & $9.82 \pm 2.59$ & $1.44 \pm 0.52 * *$ \\
Control & $R=0.28 \mathrm{e}^{-10.13 t}+0.72 \mathrm{e}^{-0.16 t}$ & $15.17 \pm 2.06$ & $2.51 \pm 0.50$ \\
\hline
\end{tabular}

* Significant $(p<0.05)$ differences between the treatments and control; ** Significant $(p<0.01)$ differences between the treatments and control.

Table 4. The $95 \%$ decomposition period $\left(T_{0.95}\right)$ and half-life period $\left(T_{0.50}\right)$ of L. gmelinii litter decomposition under different treatments.

\begin{tabular}{cccc}
\hline Medicinal Herb Extract & Litter Decomposition Model & $\boldsymbol{T}_{\mathbf{0 . 9 5}}(\mathbf{y r})$ & $\boldsymbol{T}_{\mathbf{0 . 5 0}}(\mathbf{y r})$ \\
\hline T. mongolicum & $R=0.28 \mathrm{e}^{-22.18 t}+0.72 \mathrm{e}^{-0.55 t}$ & $6.52 \pm 1.12$ & $0.72 \pm 0.08$ \\
C. bungeana & $R=0.36 \mathrm{e}^{-20.32 t}+0.63 \mathrm{e}^{-0.30 t}$ & $5.35 \pm 0.30$ & $0.73 \pm 0.05$ \\
M. haplocalyx & $R=0.36 \mathrm{e}^{-18.21 t}+0.64 \mathrm{e}^{-0.21 t}$ & $9.28 \pm 1.88$ & $0.85 \pm 0.15$ \\
H. cordata & $R=0.26 \mathrm{e}^{-34.67 t}+0.74 \mathrm{e}^{-0.56 t}$ & $12.17 \pm 0.90 *$ & $1.16 \pm 0.12 * *$ \\
A. sieboldii & $R=0.27 \mathrm{e}^{-19.51 t}+0.73 \mathrm{e}^{-0.78 t}$ & $4.91 \pm 0.47$ & $0.72 \pm 0.05$ \\
L. japonica & $R=0.40 \mathrm{e}^{-13.13 t}+0.60 \mathrm{e}^{-0.22 t}$ & $3.52 \pm 0.31$ & $0.48 \pm 0.02$ \\
N. cataria & $R=0.22 \mathrm{e}^{-4284.04 t}+0.79 \mathrm{e}^{-0.95 t}$ & $12.56 \pm 2.31 * *$ & $0.91 \pm 0.15$ \\
G. pentaphyllum & $R=0.31 \mathrm{e}^{-19.94 t}+0.69 \mathrm{e}^{-0.50 t}$ & $2.95 \pm 0.26 *$ & $0.48 \pm 0.03$ \\
P. vulgaris & $R=0.32 \mathrm{e}^{-17.63 t}+0.68 \mathrm{e}^{-0.42 t}$ & $6.03 \pm 1.16$ & $0.68 \pm 0.11$ \\
Control & $R=0.34 \mathrm{e}^{-14.85 t}+0.66 \mathrm{e}^{-0.38 t}$ & $6.37 \pm 0.28$ & $0.74 \pm 0.03$ \\
\hline
\end{tabular}

* Significant $(p<0.05)$ differences between the treatments and control; ${ }^{* *}$ Significant $(p<0.01)$ differences between the treatments and control. 


\subsection{Effects on the $N$ and $P$ Release of Conifer Litters}

Generally, the trends of the $\mathrm{N}$ and $\mathrm{P}$ release were quite different from those of the litter decomposition (mass loss). Based on the results of the repeated-measures ANOVA, the decomposition duration significantly affected the $\mathrm{N}$ and $\mathrm{P}$ release of the tested litters $(p<0.001)$. Both the $\mathrm{N}$ and $\mathrm{P}$ contents exhibited significant fluctuations during decomposition, and in one or two cases, a marked net $\mathrm{N}$ or $\mathrm{P}$ accumulation was observed (Figure 1). The medicinal herb extracts did not alter these general patterns. However, they exhibited significant effects on the N or P release $(p<0.001)$, and notably, the extracts exhibited more obvious effects on the release of $\mathrm{N}$. In addition, there were significant interaction effects between the decomposition duration and herb extract treatments $(p<0.001$, Figure 1$)$.

Specifically, for the P. armandii litter, the $\mathrm{N}$ and $\mathrm{P}$ release was significantly $(p<0.05)$ inhibited from the 1st to the 3rd months of decomposition; only the TM and DP extracts significantly accelerated its $\mathrm{N}$ release at the $3 \mathrm{rd}$ month, while the AS and HC extracts significantly $(p<0.05)$ inhibited its $\mathrm{P}$ release at the 2nd month. At the end of the tests, the extracts of $\mathrm{CB}, \mathrm{AS}, \mathrm{NC}$ and GP significantly $(p<0.05)$ inhibited the $\mathrm{N}$ release, while those of TM, CB, HC and AS significantly $(p<0.05)$ inhibited the $\mathrm{P}$ release. In contrast, the HC extracts significantly $(p<0.05)$ accelerated the $\mathrm{N}$ release, while the MH, LJ, NC, GP and PV extracts significantly $(p<0.05)$ accelerated the P release. For the L. gmelinii litter, the effects of medicinal herb extracts did not exhibit an obvious influence on the nutrient release during the first 5 months of decomposition. However, at the end of the decomposition, the CB, HC and AS extracts significantly $(p<0.05)$ inhibited the $\mathrm{N}$ release, and these three types of extracts, along with the MH, LJ, and NC extracts, exhibited significant $(p<0.05)$ inhibitory effects on the P release of the L. gmelinii litter.
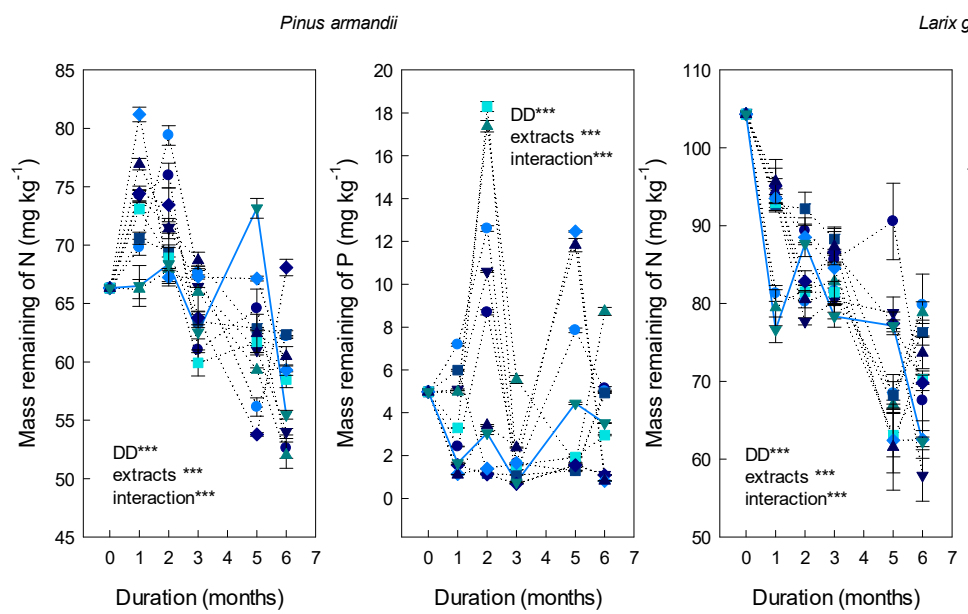

arix gmelinii

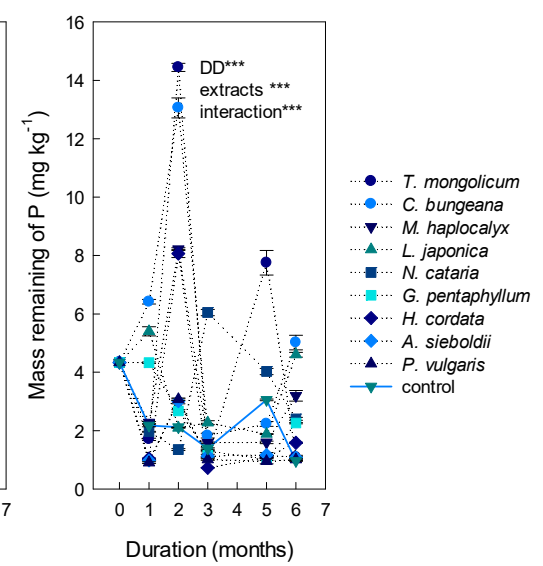

Figure 1. The $\mathrm{N}$ and $\mathrm{P}$ dynamics of the decomposition of 2 types of litter in different treatments. Significant effects from the repeated-measures analysis of variance (ANOVA) are represented as text in the subgraphs. "DD" indicates the decomposition duration effect, "extracts" indicate the effects of the herb extract treatment, and "interaction" indicates the interaction effects of the mentioned factors; ***, $p<0.001$. The same is true below.

\subsection{Effects on Soil Enzymatic Activities}

The decomposition duration, the extract treatments and their interactions also significantly (all three $p$ values were smaller than 0.001, based on the repeated-measures ANOVA) affected the activities of the soil enzymes participating in the litter decomposition and $\mathrm{N}$ and $\mathrm{P}$ cycling (Figures 2 and 3), especially those participating in the litter decomposition.

For the decomposition medium of the P. armandii litter, all extracts, except for those from PV, GP and NC, significantly $(p<0.05)$ accelerated the activity of CMCase, which mainly participates in the decomposition of moderate labile substrates during the middle and later periods of decomposition (Figure 2). However, the mentioned extracts significantly $(p<0.05)$ inhibited the activity of polyphenol 
oxidase, which mainly participates in the decomposition of recalcitrant substrates, during the early and late periods of decomposition. The TM, CB, AS and PV extracts significantly $(p<0.05)$ accelerated the activity of sucrase, which participates mainly in the decomposition of labile substrates, during the early period of decomposition, while the $\mathrm{MH}, \mathrm{HC}$ and LJ extracts significantly $(p<0.05)$ accelerated the activity of $\beta$-glucosidase during the late period. The NC and GP extracts significantly $(p<0.05)$ inhibited the activities of CMCase and polyphenol oxidase during the early and middle periods. Only the CB and MH extracts significantly $(p<0.05)$ inhibited the activity of protease, while the LJ extract significantly $(p<0.05)$ accelerated the protease activity during the early period. Only the MH and AS extracts significantly $(p<0.05)$ accelerated the activity of phosphatase during the middle and late periods of decomposition.
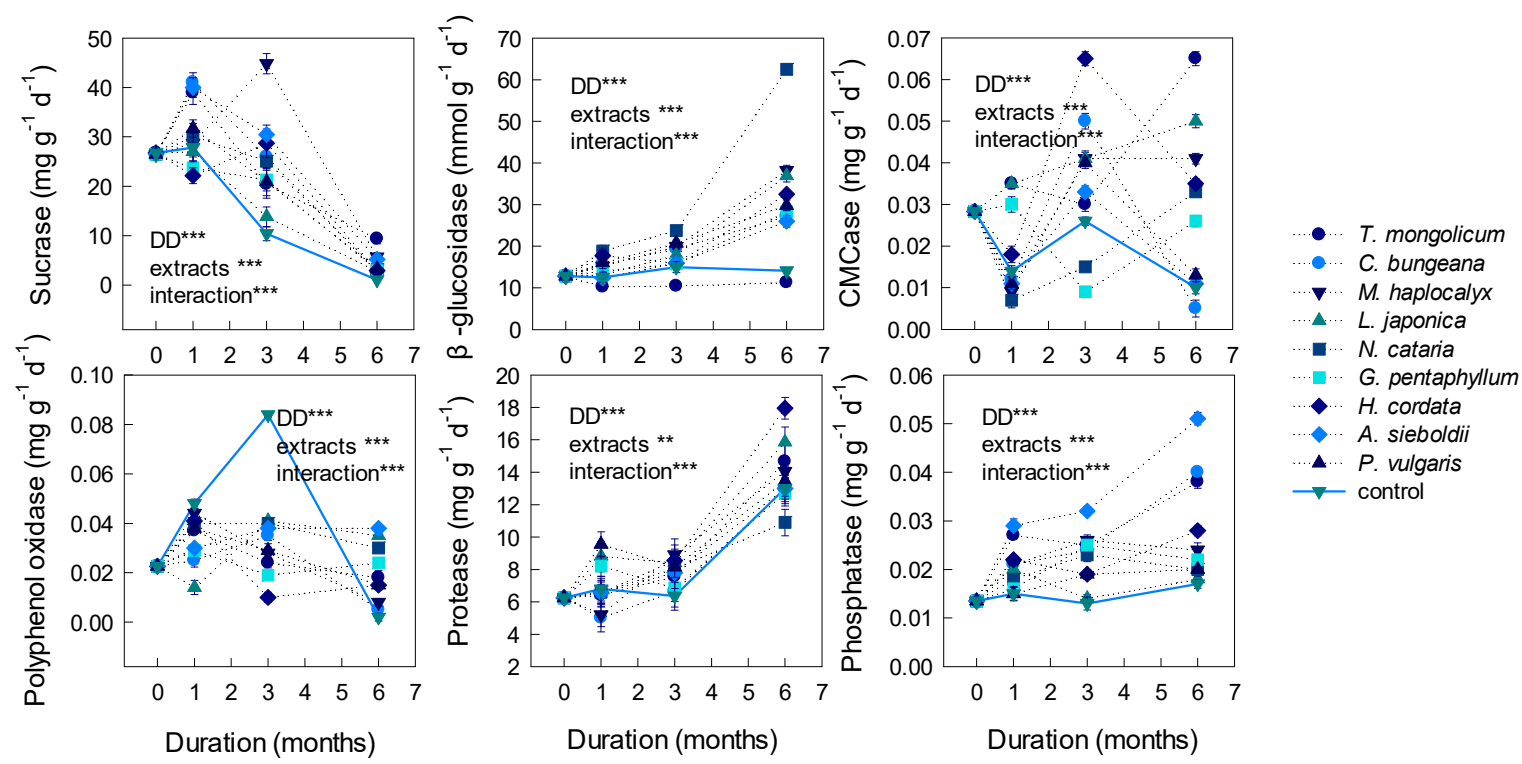

Figure 2. The enzymatic activity dynamics of the decomposition medium of the P. armandii litter under different treatments. ${ }^{* *}, p<0.01,{ }^{* *}, p<0.001$.
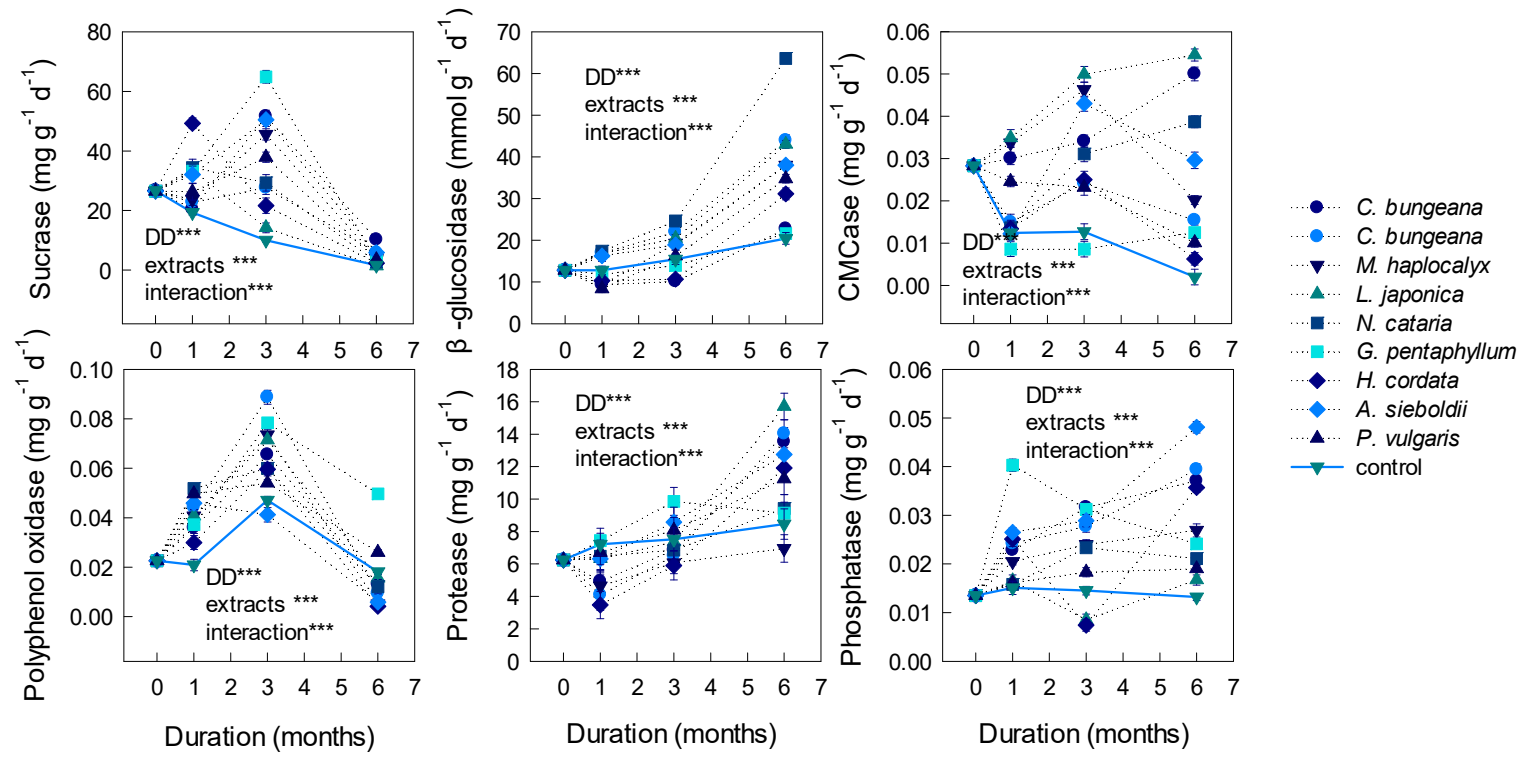

Figure 3. The enzymatic activity dynamics of the decomposition medium of the L. gmelinii litter under different treatments. ${ }^{* * *}, p<0.001$.

Relative to that of the P. armandii litter, the soil enzymatic activity of the L. gmelinii litter was rarely affected (Figure 3). Only the CB, MH, HC, AS and NC extracts significantly $(p<0.05)$ inhibited the 
activity of polyphenol oxidase during the late period of decomposition, while the GP and PV extracts exhibited opposite effects. The CB, NC, MH, AS, and LJ extracts significantly $(p<0.05)$ accelerated the activities of glucosidase and $\mathrm{CMCase}$ during the middle period of decomposition, respectively. Only the CB and HC extracts significantly $(p<0.05)$ inhibited the activity of protease during the early period, while the TM and GP extracts exhibited significant $(p<0.05)$ accelerating effects on the activity of phosphatase during the middle period of decomposition.

\section{Discussion}

\subsection{Litter Decomposition}

The results indicated that all the medicinal herb extracts, apart from TM, significantly affected the decomposition of the P. armandii litter, and that generally $(66.7 \%)$ the first half of its decomposition was accelerated while the second half was inhibited. These results were similar to the findings of Lin et al. [26], who found that P. massoniana extracts significantly inhibited the decomposition of Quercus variabilis litter at high concentrations but significantly accelerated the decomposition at lower concentrations. These effects might be attributed to the concentrations of PSMs and the contents of nutrients in the medicinal herb extracts. As mentioned above, the phenolic, terpenoid, sterol or alkaloidal components in extracts might exhibit significant inhibitory effects on decomposers and enzymes $[14,24,27-30]$ and, consequently, on the decomposition of litter. However, PSMs only exhibit inhibitory effects at certain concentrations. The concentration in this study might be relatively low because only short-term leaching caused by precipitation was simulated. Hence, during the early decomposition period, PSMs might not accumulate to the critical concentration. They might even be used as carbon sources for the microbes; thus, the treatments would not affect the decomposition of litter or might even cause acceleration [26,27]. In addition, variable nutrients were present in the extracts, such as ammonium or nitrate nitrogen [31], primary metabolites, simple sugars, amino acids, and vitamins ([32], Table 2). According to the $\mathrm{N}$ and $\mathrm{P}$ concentrations listed in Table 2, the extracts introduced 1.52 5.80 $\mathrm{mg}$ of $\mathrm{N}$ and $0.05 \sim 1.25 \mathrm{mg}$ P into the soil at each application. These substances provide extra nutrients to decomposers, thus accelerating their metabolic activity to some extent and consequently accelerating the litter decomposition. For instance, all extracts except those of PV, GP and NC significantly increased the activity of CMCase, and 4 types of extracts significantly increased the activity of sucrase, which was consistent with the findings of Adamczyk et al. [27], Lin et al. [26] and $\mathrm{Li}$ [33]. The increases in the activities of the abovementioned enzymes indicated increases in the microbial ability to utilize labile litter components.

However, due to the continuous inputs of extracts, the evaporation of water, and the rapid nutrient consumption, the PSMs that were difficult for microbes to utilize would accumulate in the soil and litter. These PSMs would exhibit significant inhibitory effects on decomposers when their concentrations reached critical values, thus leading to inhibitory effects on the late period decomposition. According to the existing literature, the camphor and borneol in the LJ extracts (Table 2, Table S1) decrease the edibility of the litter, hindering the gnawing of the soil fauna. These PSMs also exhibit significant inhibitory effects on the spore germination and growth of Penicillium and Aspergillus microbes, which participate in the decomposition of cellulose [34,35]. The pinene in the CB, MH and PV extracts can destroy the cell structure of Bacillus bacteria and lead to their death [36]. The linalool (Table 2, Table S1) in the CB, GP and PV extracts could simultaneously inhibit the growth of Pseudomonas (capable of decomposing lignin), Bacillus (capable of decomposing cellulose), and Aspergillus microbes [37]. The quercetin found in the TM and HC extracts significantly inhibits the growth of Bacillus spp. [38].

In addition, PSMs also exhibited bacteriostasis when they coexisted. Previous studies stated that plant extracts containing pinene and linalool significantly inhibit the growth of two types of highly effective lignin-decomposing fungi, Coriolus versicolor and Gloeophyllum trabeum (Table 2, Table S1) [39], while extracts containing myrcene, caryophyllene, pinene, and linalool exhibited significant inhibitory 
effects on Pseudomonas, Bacillus and Aspergillus microbes (Table 2, Table S1) [40]. All mentioned PSM groups were found in the extracts in this study (e.g., in the CB, HC and PV extracts).

In view of the ability of microbes to utilize both labile and recalcitrant carbon sources, medicinal herb extracts also affected the activity of related enzymes. For example, the activity of polyphenol oxidase was significantly inhibited during the middle and late periods of decomposition (Figures 2 and 3), which was similar to the findings of Ushio et al. [22] and Adamczyk et al. [14], who stated that PSMs such as phenolic derivatives, $\alpha$-pinene, and myrcene significantly inhibit the activity of polyphenol oxidase. A possible reason for this might be that the decreases in enzyme secretion caused decreases in the microbial populations.

The inhibitory effects on the catalytic ability of the ectoenzymes of PSMs also contributed to the decreases in enzymatic activities. For example, the accumulation of acid compounds, such as palmitic acid, pentadecylic acid and caffeic acid, detected in the LJ, NC, GP and PV extracts (Table 2, Table S1), would certainly lead to soil acidification and decrease the activity of enzymes by altering their conformation [41,42]. Most importantly, the phenolic acids, terpenes and sterol compounds generally detected in variable extracts, such as pinene, myrcene and $\beta$-sitosterol, can cause protein precipitation and the consequent inactivation of enzymes $[14,23,24]$. In the study, the decreases in the polyphenol oxidase activity in the late decomposition period might be caused by enzymatic inactivation resulting from the combination of the accumulated PSMs and enzymes.

Notably, in some cases, the medicinal herb extracts exhibited no significant effects (TM extract) or significant accelerating effects (HC and AS extracts) on the conifer litter decomposition. The reason for this might be that the PSM content in these extracts was relatively low and could therefore not accumulate to the critical concentration for inhibitory effects, even during the late period of decomposition. In addition, the nutrients in these extracts caused accelerating effects that covered the inhibitory effects of the PSMs. Moreover, a variety of types of PSMs were detected in the abovementioned extracts, and antagonistic effects among PSMs might weaken their antibacterial effects [30], leading to limited effects on the conifer litter decomposition. Due to the lack of literature, the possibility of antagonistic or synergistic effects among PSMs requires further investigation.

Relative to the P. armandii litter, the decomposition of the L. gmelinii litter was less readily inhibited by the medicinal herb extracts (Table 3). This difference might be attributed to the differences in litter quality between the two types of litter. The L. gmelinii litter has a significantly higher $\mathrm{N}$ content, as well as a significantly lower lignin content and $\mathrm{C} / \mathrm{N}, \mathrm{C} / \mathrm{P}$, lignin/ $\mathrm{N}$ and lignin/P ratios than the P. armandii litter, making it a much higher-quality substrate (Table 1). Consequently, the L. gmelinii litter could provide a much better nutrient environment for microbes, which would alleviate the inhibitory effects caused by PSMs on the growth of microbes and their metabolic activity. The rare effects of PSMs on the enzymes in the decomposition of the L. gmelinii litter (Figures 2 and 3) also confirmed this hypothesis. In addition, out of the four types of C-utilizing enzymes, polyphenol oxidase, which mainly participates in the decomposition of lignin, was generally inhibited. Hence, the low concentration of lignin in the L. gmelinii litter resulted in the rare inhibitory effects caused by the PSMs. In addition, the differences in substrate quality would cause significant differences in the microbial species and community traits [43] and, consequently, different responses to the same PSMs and to the same medicinal herb extracts.

\subsection{Nutrient Release}

Similar to previous studies, the release of $\mathrm{N}$ and $\mathrm{P}$ from the two types of litter exhibited totally different trends in terms of the mass loss, while exhibiting obvious fluctuations and intermittent enrichments [44]. This result was attributed to the microbes requiring given nutrient stoichiometric ratios and tending to accumulate nutrients from their environment when the litter $\mathrm{C} / \mathrm{N}$ and $\mathrm{C} / \mathrm{P}$ ratios were relatively high [45].

In the first half of the decomposition, the $\mathrm{N}$ and $\mathrm{P}$ releases from the $P$. armandii litter were significantly inhibited, which was in line with previous findings $[46,47]$. Considering the simultaneous acceleration of the decomposition, these inhibitory effects might be attributed to the C-utilizing 
decomposer bloom consuming a mass of $\mathrm{N}$ and $\mathrm{P}$, leading to $\mathrm{N}$ and $\mathrm{P}$ immobilization from the soil. In this study, the activities of protease and phosphatase were rarely affected by PSMs relative to C-consuming enzymes, which was contrary to the results of previous studies $[14,16,22]$. This might be because the microbes were forced to secrete these enzymes to obtain sufficient nutrients, consequently covering the decreases in enzymatic activities. At the end of the decomposition, most (80\%) types of extracts still significantly inhibited the $\mathrm{N}$ release, while the amounts of the extract types accelerating or inhibiting the P release were approximately equal ( 5 types/4 types). Considering that during the late period of decomposition the decomposition process was still inhibited, the first reason for the suppressed nutrient release might be that the PSMs inhibited the decomposition (structure break of litter), hindering the $\mathrm{N}$ and $\mathrm{P}$ release. Second, the concentrations of polyphenols and lignin in litter usually increase during the late period. Nitrogen combines with these recalcitrant substances, which could hinder the $\mathrm{N}$ release [48]. This might be why the $\mathrm{N}$ release was more likely to be hindered than the $P$ release. In contrast, due to the death of the microbes, cell lysis, alterations in the membrane permeability, and hyphae fracture caused by PSMs $[49,50]$, the P immobilized in cells might be released, leading to an apparent accelerated $P$ release.

The $\mathrm{N}$ and $\mathrm{P}$ release from the L. gmelinii litter was also rarely affected in the first half of the decomposition, which might be attributed to its better substrate quality; thus, its decomposition was not obviously inhibited. Similarly, during the late-period decomposition, the L. gmelinii litter, which is relatively rich in nutrients (except for $\mathrm{P}$, Table 1 ) and which has a better water absorption capacity (unpublished data), could also provide much better humidity and nutrient sources to microbes and protect the microbes from death under increasing PSM stress. Consequently, N and P were still immobilized in microbes, rather than being released.

It should be noted that the $\mathrm{N}$ and $\mathrm{P}$ in the environment (i.e., in soil, for litter) would affect the $\mathrm{N}$ and $\mathrm{P}$ release from litter, and there were certainly $\mathrm{N}$ and $\mathrm{P}$ inputs from the herb extract treatments. However, the largest $\mathrm{N}$ inputs ( $5.80 \mathrm{mg}$ every time, with a concentration of $38.69 \mathrm{mg} \mathrm{L}^{-1}$ ) and $\mathrm{P}$ inputs $\left(1.25 \mathrm{mg}\right.$ every time, with a concentration of $8.35 \mathrm{mg} \mathrm{L}^{-1}$ ) caused by the extract treatment were quite small relative to the $\mathrm{N}$ and $\mathrm{P}$ contents in the litter or soil (Section 2.1., and Table 1). Furthermore, these inputs were diluted by the soil as they were uniformly sprayed into the soil, while most of the soil did not come into contact with the litter. Consequently, these inputs might affect the populations of microbes to some extent, as mentioned in Section 4.1., but would rarely affect their $\mathrm{N}$ and $\mathrm{P}$ metabolism or the related $\mathrm{N}$ and $\mathrm{P}$ release.

\section{Conclusions}

(1) Most of the tested medicinal herb extracts significantly $(p<0.05)$ inhibited the late decomposition of the $P$. armandii litter, while only the $H$. cordata and $A$. sieboldii extracts accelerated the entire decomposition process. Only the H. cordata, N. cataria and G. pentaphyllum extracts significantly $(p<0.05)$ affected the decomposition of the L. gmelinii litter.

(2) Four of the nine types of extracts significantly inhibited the $\mathrm{N}$ and $\mathrm{P}$ release of the P. armandii litter, while 3/9 and 6/9 inhibited the $\mathrm{N}$ and $\mathrm{P}$ release of the L. gmelinii litter, respectively.

(3) The accelerating effects of the extracts on the cellulase activity and the inhibitory effects on the polyphenol oxidase activity might be responsible for the early acceleration and late inhibition of litter decomposition, while the effects of the extracts on the activities of protease and phosphatase might not be the main cause of the inhibitory or accelerating effects on the $\mathrm{N}$ and $\mathrm{P}$ release.

(4) In general, the inhibitory effects of medicinal herbs on the nutrient cycling of ecosystems should be taken into consideration when building silvi-medicinal systems, especially in P. armandii forests.

Supplementary Materials: The following are available online at http:/www.mdpi.com/2071-1050/11/18/5138/ s1, Table S1: Decomposition-related microbes and enzymes inhibited by PSMs from herb extracts based on the literature. 
Author Contributions: Conceptualization, Z.X. and L.Z.; methodology, Z.X.; experiments, Z.X., L.H., C.Y., H.J., C.W., H.M., X.S., Z.P. and X.J; data processing, Z.X.; writing-original draft preparation, X.X.; funding acquisition, Z.X.

Funding: This research was funded by the National Natural Science Foundation of China [31800370], the Natural Science Basic Research Plan in Shaanxi Province of China [2018JQ4047], the Young Talent Fund of University Association for Science and Technology in Shaanxi, China [20170704], the Specialized Research Fund for the Doctoral Program of Yan'an University [YDBK2017-26] and the College Students Innovation and Entrepreneurship Training Program [201910719027; D2017082].

Acknowledgments: The authors thank Yupeng Lu, Miss Boya Wang and Bo Xie for their help with the experiments.

Conflicts of Interest: The authors declare no conflict of interest.

\section{References}

1. Chao, J.; Dai, Y.; Verpoorte, R.; Lam, W.; Cheng, Y.-C.; Pao, L.-H.; Zhang, W.; Chen, S. Major achievements of evidence-based traditional Chinese medicine in treating major diseases. Biochem. Pharmacol. 2017, 139, 94-104. [CrossRef] [PubMed]

2. Normile, D. The new face of traditional Chinese medicine. Science 2003, 299, 188-190. [CrossRef] [PubMed]

3. Wang, J.; Sasse, A.; Sheridan, H. Traditional Chinese Medicine: From Aqueous Extracts to Therapeutic Formulae. In Plant Extracts; IntechOpen: Rijeka, Croatia, 2019.

4. Duke, J.A. Duke's Handbook of Medicinal Plants of Latin America; CRC Press: Boca Raton, FL, USA, 2008.

5. Li, T.S. Chinese \& Related North American Herbs: Phytopharmacology \& Therapeutic Values, 2nd ed.; CRC Press: Boca Raton, FL, USA, 2016.

6. Wiśniewski, J.; Szczepanik, M.; Kołodziej, B.; Król, B. Plantation methods effects on common valerian (Valeriana officinalis) yield and quality. J. Anim. Plant Sci. 2016, 26, 177-184.

7. Hu, L.; Zhang, Z.; Wang, W.; Wang, L.; Yang, H. Ginseng plantations threaten China's forests. Biodivers Conserv. 2018, 27, 2093-2095. [CrossRef]

8. Li, Y.; Wang, B.; Chang, Y.; Yang, Y.; Yao, C.; Huang, X.; Zhang, J.; Cai, Z.; Zhao, J. Reductive soil disinfestation effectively alleviates the replant failure of Sanqi ginseng through allelochemical degradation and pathogen suppression. Appl. Microbiol. Biotechnol. 2019, 103, 3581-3595. [CrossRef] [PubMed]

9. Dong, L.; Xu, J.; Feng, G.; Li, X.; Chen, S. Soil bacterial and fungal community dynamics in relation to Panax notoginseng death rate in a continuous cropping system. Sci. Rep. 2016, 6, 31802. [CrossRef] [PubMed]

10. Zhou, Y.; Li, S.; Li, B.; Ren, X. Evaluation of important medicinal plant resources in Qinling Mountains based on analytic hierarchy process method. Chin. Traditional. Herb. Drug 2013, 44, 2172-2182.

11. Zhang, X.; Liu, H.; Wang, B.; Li, J.; Lei, H.; Liu, Z. Characteristics of the mixed decomposition of fresh litter of Picea asperata and broadleaved species. Ecol. Environ. Sci. 2019, 28, 235-244.

12. Sanwal, C.S.; Kumar, R.; Anwar, R.; Kakade, V.; Kerketta, S.; Bhardwaj, S. Growth and yield of Solanum khasianum in Pinus roxburghii forest based silvi-medicinal system in mid hills of Indian Himalaya. For. Ecosyst. 2016, 3, 19-27. [CrossRef]

13. Song, X.; Jiang, H.; Yu, S.; Ma, Y.; Zhou, G.; Dou, R.; Guo, P. Litter decomposition of dominant plant species in successional stages in mid-subtropical zone. Chin. J. Appl. Ecol. 2009, 20, 537-542.

14. Adamczyk, S.; Adamczyk, B.; Kitunen, V.; Smolander, A. Monoterpenes and higher terpenes may inhibit enzyme activities in boreal forest soil. Soil. Biol. Biochem. 2015, 87, 59-66. [CrossRef]

15. Pitarokili, D.; Couladis, M.; Petsikos-Panayotarou, N.; Tzakou, O. Composition and antifungal activity on soil-borne pathogens of the essential oil of Salvia sclarea from Greece. J. Agric. Food Chem. 2002, 50, 6688-6691. [CrossRef] [PubMed]

16. Zhang, Z.; Qiao, M.; Li, D.; Zhao, C.; Li, Y.; Yin, H.; Liu, Q. Effects of two root-secreted phenolic compounds from a subalpine conifer species on soil enzyme activity and microbial biomass. Chem. Ecol. 2015, 31, 636-649. [CrossRef]

17. Zhou, B.; Kong, C.-H.; Li, Y.-H.; Wang, P.; Xu, X.-H. Crabgrass (Digitaria sanguinalis) allelochemicals that interfere with crop growth and the soil microbial community. J. Agric. Food Chem. 2013, 61, 5310-5317. [CrossRef] [PubMed]

18. Li, Y.; Ying, Y.; Zhao, D.; Ding, W. Influence of allelochemicals on microbial community in ginseng cultivating soil. Chin. Herb. Med. 2014, 6, 313-318. [CrossRef] 
19. Kong, C.; Wang, P.; Zhao, H.; Xu, X.; Zhu, Y. Impact of allelochemical exuded from allelopathic rice on soil microbial community. Soil Biol. Biochem. 2008, 40, 1862-1869. [CrossRef]

20. Hättenschwiler, S.; Jørgensen, H.B. Carbon quality rather than stoichiometry controls litter decomposition in a tropical rain forest. J. Ecol. 2010, 98, 754-763. [CrossRef]

21. Medvedeff, C.A.; Bridgham, S.D.; Pfeifer-Meister, L.; Keller, J.K. Can Sphagnum leachate chemistry explain differences in anaerobic decomposition in peatlands? Soil Biol. Biochem. 2015, 86, 34-41. [CrossRef]

22. Ushio, M.; Balser, T.C.; Kitayama, K. Effects of condensed tannins in conifer leaves on the composition and activity of the soil microbial community in a tropical montane forest. Plant Soil 2013, 365, 157-170. [CrossRef]

23. Triebwasser, D.J.; Tharayil, N.; Preston, C.M.; Gerard, P.D. The susceptibility of soil enzymes to inhibition by leaf litter tannins is dependent on the tannin chemistry, enzyme class and vegetation history. New Phytol. 2012, 196, 1122-1132. [CrossRef]

24. Adamczyk, S.; Kiikkilä, O.; Kitunen, V.; Smolander, A. Potential response of soil processes to diterpenes, triterpenes and tannins: Nitrification, growth of microorganisms and precipitation of proteins. Appl. Soil Ecol. 2013, 67, 47-52. [CrossRef]

25. Zhang, X.; Hu, W.; Liu, Z. Soil Response of nutrient release of Periploca sepium litter to soil petroleum contamination. Clean Soil Air Water 2016, 44, 1709-1716. [CrossRef]

26. Lin, H.; Zhao, Y.; Muyidong, N.; Tian, K.; He, Z.; Kong, X.; Sun, S.; Tian, X. Secondary compounds of Pinus massoniana alter decomposers' effects on Quercus variabilis litter decomposition. Ecol. Evol. 2018, 8, 9439-9450. [CrossRef] [PubMed]

27. Adamczyk, B.; Karonen, M.; Adamczyk, S.; Engström, M.T.; Laakso, T.; Saranpää, P.; Kitunen, V.; Smolander, A.; Simon, J. Tannins can slow-down but also speed-up soil enzymatic activity in boreal forest. Soil Biol. Biochem. 2017, 107, 60-67. [CrossRef]

28. Aggarwal, K.; Khanuja, S.; Ahmad, A.; Santha Kumar, T.; Gupta, V.K.; Kumar, S. Antimicrobial activity profiles of the two enantiomers of limonene and carvone isolated from the oils of Mentha spicata and Anethum sowa. Flavour Fragr. J. 2002, 17, 59-63. [CrossRef]

29. Yang, S.; Jiang, D.; Fan, G.; Zhang, Q.; Li, M.; Cheng, Y.; Peng, L. Antifungal activity against citrus blue mold and its active constituents of solvent extracts from pine needles. Mod. Food Sci. Technol. 2016, 32, 65-69.

30. Chomel, M.; Guittonny-Larchevêque, M.; Fernandez, C.; Gallet, C.; DesRochers, A.; Paré, D.; Jackson, B.G.; Baldy, V. Plant secondary metabolites: A key driver of litter decomposition and soil nutrient cycling. J. Ecol. 2016, 104, 1527-1541. [CrossRef]

31. Del Giudice, R.D.; Lindo, Z. Short-term leaching dynamics of three peatland plant species reveals how shifts in plant communities may affect decomposition processes. Geoderma 2017, 285, 110-116. [CrossRef]

32. Wei, C.; Liu, X.; Lin, C.; Li, X.; Li, Y.; Zheng, Y. Response of soil enzyme activities to litter input changes in two secondary Castanopsis carlessii forests in subtropical China. Chin. J. Plant Ecol. 2018, 42, 692-702.

33. Li, C. Effect of exogenous allelochemical vanillic acid on soil enzyme activity and soil nutrient for pepper seedling. China Veg. 2009, 2009, 46-49.

34. Chen, W.; Vermaak, I.; Viljoen, A. Camphor-a fumigant during the black death and a coveted fragrant wood in ancient Egypt and Babylon-a review. Molecules 2013, 18, 5434-5454. [CrossRef] [PubMed]

35. Shi, B.; Luan, D.; Wang, S.; Zhao, L.; Tao, L.; Yuan, Q.; Wang, X. Borneol-grafted cellulose for antifungal adhesion and fungal growth inhibition. RSC Adv. 2015, 5, 51947-51952. [CrossRef]

36. Cho, W.-I.; Cheigh, C.-I.; Hwang, H.-J.; Chung, M.-S. Sporicidal activities of various surfactant components against Bacillus subtilis spores. J. Food Prot. 2015, 78, 1221-1225. [CrossRef] [PubMed]

37. Pattnaik, S.; Subramanyam, V.; Bapaji, M.; Kole, C. Antibacterial and antifungal activity of aromatic constituents of essential oils. Microbios 1997, 89, 39-46. [PubMed]

38. Mancini, A.; Pucciarelli, S. Antibiotic activity of the antioxidant drink effective Microorganism-X (EM-X) extracts against common nosocomial pathogens: An in vitro study. Nat. Prod. Res. 2018, 1-6. [CrossRef] [PubMed]

39. Li, Q. Research on Chemical Composition and Decay Resistance Mechanism of Cinnamomum camphora Wood Extracts. Ph.D. Thesis, Fujian Agricultural and Forestry University, Fuzhou, China, 2014.

40. Skočibušić, M.; Bezić, N.; Dunkić, V. Phytochemical composition and antimicrobial activities of the essential oils from Satureja subspicata Vis. growing in Croatia. Food Chem. 2006, 96, 20-28. [CrossRef] 
41. Liu, P.; Liu, Z.; Wang, C.; Guo, F.; Wang, M.; Zhang, Y.; Dong, L.; Wan, S. Effects of three long-chain fatty acids present in peanut (Arachis hypogaea L.) root exudates on its own growth and the soil enzymes activities. Allelopath. J. 2012, 29, 13-24.

42. Guan, Z.; Luo, Q.; Chen, X.; Feng, X.; Tang, Z.; Wei, W.; Zheng, Y. Saline soil enzyme activities of four plant communities in Sangong River basin of Xinjiang, China. J. Arid Land 2014, 6, 164-173. [CrossRef]

43. Yang, K.; Zhu, J.J. Impact of tree litter decomposition on soil biochemical properties obtained from a temperate secondary forest in Northeast China. J. Soils Sediments 2015, 15, 13-23. [CrossRef]

44. Berger, T.W.; Olivier, D.; Ika, D.; Michael, T.; Gerzabek, M.H.; Franz, Z. Decomposition of beech (Fagus sylvatica) and pine (Pinus nigra) litter along an Alpine elevation gradient: Decay and nutrient release. Geoderma 2015, 251, 92-104. [CrossRef]

45. Schimel, J.P.; Hättenschwiler, S. Nitrogen transfer between decomposing leaves of different N status. Soil Biol. Biochem. 2007, 39, 1428-1436. [CrossRef]

46. Smolander, A.; Kanerva, S.; Adamczyk, B.; Kitunen, V. Nitrogen transformations in boreal forest soils-Does composition of plant secondary compounds give any explanations? Plant Soil 2012, 350, 1-26. [CrossRef]

47. Lu, Y.; Xu, J.; Zhang, X.; Wang, B.; Xie, B.; Liu, Z. Effects of leachate from understory medicinal plants on litter decomposition and soil enzyme activities of Betula albo-sinensis and Eucommia ulmoides. Chin. J. Plant Ecol. 2017, 41, 639-649.

48. Yang, Q.; Li, R.; Zhang, W.; Zheng, W.; Wang, Q.; Chen, L.; Guan, X.; Xu, M.; Wang, S. Decomposition of harvest residue needles of different needle ages in a Chinese fir (Cunninghamia lanceolata) plantation. Plant Soil 2018, 423, 273-284. [CrossRef]

49. Shao, X.; Cheng, S.; Wang, H.; Yu, D.; Mungai, C. The possible mechanism of antifungal action of tea tree oil on Botrytis cinerea. J. Appl. Microbiol. 2013, 114, 1642-1649. [CrossRef] [PubMed]

50. Cox, S.; Mann, C.; Markham, J.; Bell, H.; Gustafson, J.; Warmington, J.; Wyllie, S. The mode of antimicrobial action of the essential oil of Melaleuca alternifolia (tea tree oil). J. Appl. Microbiol. 2000, 88, 170-175. [CrossRef] [PubMed]

(C) 2019 by the authors. Licensee MDPI, Basel, Switzerland. This article is an open access article distributed under the terms and conditions of the Creative Commons Attribution (CC BY) license (http://creativecommons.org/licenses/by/4.0/). 